\title{
Toward a complete estimate of physical and psychosocial morbidity from prolonged obstructed labour: a modelling study based on clinician survey
}

\author{
Lina Roa (D) , ${ }^{1,2}$ Luke Caddell,, ${ }^{1,3}$ Gabriel Ganyaglo, ${ }^{4}$ Vandana Tripathi, ${ }^{5}$ \\ Nazmul Huda, ${ }^{6}$ Lauri Romanzi, ${ }^{1,5}$ Blake C Alkire ${ }^{1,7,8}$
}

To cite: Roa L, Caddell L, Ganyaglo G, et al. Toward a complete estimate of physical and psychosocial morbidity from prolonged obstructed labour: a modelling study based on clinician

survey. BMJ Global Health 2020;5:e002520. doi:10.1136/ bmjgh-2020-002520

Handling editor Sanni Yaya

- Additional material is published online only. To view please visit the journal online (http://dx.doi.org/10.1136/ bmjgh-2020-002520).

LR and BCA are joint senior authors.

Received 22 March 2020 Revised 19 May 2020 Accepted 22 May 2020

Check for updates

(c) Author(s) (or their employer(s)) 2020. Re-use permitted under CC BY-NC. No commercial re-use. See rights and permissions. Published by BMJ.

For numbered affiliations see end of article.

Correspondence to

Dr Lina Roa;

Iroa123@gmail.com
ABSTRACT

Introduction Prolonged obstructed labour often results from lack of access to timely obstetrical care and affects millions of women. Current burden of disease estimates do not include all the physical and psychosocial sequelae from prolonged obstructed labour. This study aimed to estimate the prevalence of the full spectrum of maternal and newborn comorbidities, and create a more comprehensive burden of disease model.

Methods This is a cross-sectional survey of clinicians and epidemiological modelling of the burden of disease. A survey to estimate prevalence of prolonged obstructed labour comorbidities was developed for prevalence estimates of 27 comorbidities across seven categories associated with prolonged obstructed labour. The survey was electronically distributed to clinicians caring for women who have suffered from prolonged obstructed labour in Asia and Africa. Prevalence estimates of the sequelae were used to calculate years lost to disability for reproductive age women (15 to 49 years) in 54 low- and middle-income countries that report any prevalence of obstetric fistula.

Results Prevalence estimates were obtained from 132 participants. The median prevalence of reported sequelae within each category were: fistula $(6.67 \%$ to $23.98 \%$ ), pelvic floor $(6.53 \%$ to $8.60 \%)$, genitourinary (5.74\% to $9.57 \%)$, musculoskeletal $(6.04 \%$ to $11.28 \%$ ), infectious/inflammatory (5.33\% to $9.62 \%)$, psychological $(7.25 \%$ to $24.10 \%)$, neonatal $(13.63 \%$ to $66.41 \%$ ) and social (38.54\% to $59.88 \%$ ). The expanded methodology calculated a burden of morbidity associated with prolonged obstructed labour among women of reproductive age (15 to 49 years old) in 2017 that is $38 \%$ more than the previous estimates.

Conclusions This analysis provides estimates on the prevalence of physical and psychosocial consequences of prolonged obstructed labour. Our study suggests that the burden of disease resulting from prolonged obstructed labour is currently underestimated. Notably, women who suffer from prolonged obstructed labour have a high prevalence of psychosocial sequelae but these are often not included in burden of disease estimates. In addition to preventative and public health measures, high quality

\section{Key questions}

What is already known?

- Prolonged obstructed labour often results from lack of timely access to obstetrical care, particularly caesarean sections.

- Prolonged obstructed labour results in significant mortality and morbidity in women, particularly fistula.

\section{What are the new findings?}

- Women who suffered from prolonged obstructed labour have a high prevalence of a wide range of physical and psychosocial sequelae.

- The burden of disease resulting from prolonged obstructed labour is $38 \%$ more than previous estimates.

What do the new findings imply?

- The current burden of disease associated with prolonged obstructed labour likely remains an underestimate of disability, particularly related to psychosocial sequelae.

- High quality surgical and anaesthesia care are urgently needed to prevent prolonged obstructed labour and its sequelae

surgical and anaesthesia care are urgently needed to prevent prolonged obstructed labour and its sequelae.

\section{INTRODUCTION}

Obstructed labour (OL) occurs when fetal descent is blocked by an insurmountable barrier despite forceful uterine contractions, requiring early and appropriate treatment. ${ }^{1}$ Advances in obstetrical care have eradicated most complications of OL in highincome countries through access to timely and safe caesarean section (CS) and instrumental delivery. ${ }^{2-4}$ Analyses have consistently 
demonstrated the cost-effectiveness of these interventions, even in resource-limited settings. ${ }^{5-8}$ However, in areas where women's need for comprehensive obstetrical care has been neglected, the result is prolonged obstructed labour (POL). While there is a lack of consensus on the definition of prolonged labour generally, and POL specifically, ${ }^{9} 10$ there is global recognition of the impact of POL on maternal and newborn health, predominantly in sub-Saharan Africa and Asia. ${ }^{11} 12$

The lack of access to appropriate care, including surgical care, among women with POL has resulted in this condition accounting for $2.1 \%$ to $12 \%$ of maternal mortality, ${ }^{13}$ and for $29 \%$ to $44 \%$ of stillbirths. ${ }^{14}{ }^{15}$ Even when deaths are prevented, mothers and infants may suffer from one or more lifelong disabilities. For infants, intrapartum asphyxia may cause neurological damage and developmental issues. ${ }^{16}{ }^{17}$ Women contend with a varied array of physical and psychosocial sequelae that are originally referred as the OL injury complex: fistula between the urinary and gastrointestinal and genital tracts, urinary and faecal incontinence, vaginal fibrosis, cervical and vaginal stenosis, infertility, dyspareunia, sepsis, diastasis pubis, osteomyelitis, foot drop and chronic pelvic pain. ${ }^{18-20}$ POL-related mental health issues include depression and anxiety and social consequences such as experiencing stigma, divorce, abandonment, income loss and property loss; however, much of the literature documenting these issues comes from investigations of the experiences of women with fistula. ${ }^{1819} 2122$ Despite the broad range of sequelae, health programmes and research around treatment of POL have predominantly focussed on fistula repair alone. ${ }^{23} 24$

Current epidemiological analyses of the impact of POL have a limited scope. The Global Burden of Diseases, Injury and Risk Factors Study 2017 (GBD) to estimate the burden of disease (BOD) resulting from OL and uterine rupture, only takes into account maternal mortality, rectovaginal fistula (inclusive of faecal incontinence) and vesicovaginal fistula (inclusive of depression and urinary incontinence).$^{25}$ This narrow focus fails to include many sequelae and underestimates the true impact of POL.

The objective of this study was to estimate the BOD associate with POL by surveying health practitioners to estimate the prevalence of the full spectrum of POL sequelae. These estimates were used to inform a BOD model with a more comprehensive set of sequelae than is currently reported by the 2017 GBD.

\section{METHODS}

\section{Study population}

Inclusion criteria for survey participation were health practitioners from any field, working for at least 6 months in centres where women with POL are treated in Asia and Africa. The survey was distributed in English and limited to those with an understanding of written English. Given the near-complete absence of POL in health systems that provide timely access to safe CS, non-zero fistula estimates are only provided for 54 countries in the GBD study and our analysis is limited to these same countries.

\section{Survey development and distribution}

A literature search to identify existing validated questionnaires was conducted but none were found that comprehensively assessed physical and psychosocial sequelae from POL. We developed a survey questionnaire after an extensive literature review of the sequelae of POL followed by expert consensus of a multidisciplinary team of fistula surgeons, researchers and clinicians. Careful designing of the survey questionnaire took into consideration wording, form and order of the questions. In total, 27 unique sequelae previously associated with POL were chosen and grouped into eight different categories. The survey questionnaire included questions on demographics, practice type, practice location and prevalence estimates of the 27 sequelae for all women who experience POL (online supplementary appendix S1). Recognising the lack of a global consensus definition of POL, we did not provide a specific definition to respondents. Three of the survey questions addressed fistula while the remainder inquired about pelvic floor disorders, sexual and reproductive health, musculoskeletal issues, infectious diseases, mental health, neonatal outcomes and social impact.

The questionnaire was distributed via email as an anonymous multiple-choice survey in November and December of 2018. Global networks of fistula care providers were approached to send the survey to their members. The target population was clinicians that work with patients who suffered POL. Snowball sampling was used to allow for further subject recruitment. Reminder emails were sent at 2-week intervals for 6 weeks following the original invitation to participate. Data were collected and managed using a REDCap (Research Electronic Data Capture) tool. ${ }^{26}$

\section{Statistical analysis}

Measures of central tendency (mean and median) and variance ( $\mathrm{SD}$ and $\mathrm{IQR})$ were calculated using frequency tables and formulae for grouped data. Inter-rater reliability was analysed using Kendall's coefficient of concordance for ordinal data, with correction for ties. Landis and Koch criteria were then applied to the reliability estimate. Data analysis was performed using the $\mathrm{R}$ programming language through RStudio V.1.1.453. ${ }^{27} 28$

\section{Estimating years lived with disability}

To estimate years lived with disability (YLDs) for a more comprehensive set of morbidities than is currently reported by the 2017 GBD, we began by identifying which sequelae from our survey to include in an augmented YLD model. Given the desire to replicate GBD methodology for constructing YLDs to the degree feasible given our data, we began by associating each sequela with its assigned GBD disability; sequelae without disability weights were excluded from this analysis (eg, social 
Box 1 Prolonged obstructed labour comorbidity sets sequelae
Acute complications
- Acute event without sepsis.
- Acute event with sepsis.

\section{Chronic complications with fistula (includes depression} and incontinence)

- Fistula with infertility, foot drop or chronic pelvic pain.

- Fistula with infertility, without foot drop or chronic pelvic pain.

- Fistula with infertility and foot drop, without chronic pelvic pain.

- Fistula with infertility, foot drop and chronic pelvic pain.

- Fistula without infertility, foot drop or chronic pelvic pain.

- Fistula without infertility, with foot drop and chronic pelvic pain.

- Fistula without infertility or foot drop, with chronic pelvic pain.

- Fistula without infertility, with foot drop, and without chronic pelvic pain.

\section{Chronic complications without fistula}

- Asymptomatic (no incontinence, infertility, foot drop or chronic pelvic pain).

With incontinence, infertility, foot drop and chronic pelvic pain.

With incontinence, without infertility, foot drop or chronic pelvic pain.

- With incontinence and infertility, without foot drop or chronic pelvic pain.

Without incontinence, with infertility, foot drop and chronic pelvic pain.

Without incontinence and infertility, with foot drop and chronic pelvic pain.

Without incontinence, infertility and foot drop, with chronic pelvic pain.

- With incontinence, without infertility, with foot drop and chronic pelvic pain.

With incontinence, without infertility or foot drop, with chronic pelvic pain.

- With incontinence and infertility, without foot drop, with chronic pelvic pain.

With incontinence, without infertility, with foot drop, without chronic pelvic pain.

Without incontinence, with infertility, without foot drop and chronic pelvic pain.

- Without incontinence, with infertility and foot drop, without chronic pelvic pain.

Without incontinence, with infertility, without foot drop, with chronic pelvic pain.

- Without incontinence and infertility, with foot drop, without chronic pelvic pain.

Without incontinence, infertility and foot drop, with chronic pelvic pain.

impact due to loss of partnership or income). The final list of sequelae must account for comorbidities and be mutually exclusive and collectively exhaustive. Comorbidity sets are created by listing all possible permutations of individual sequela. Thus, the final list (box 1) of comorbidity sets avoids pairing sequelae that are inclusive of other sequelae (urinary incontinence and depression can be secondary to fistula and are both included as a factor in the fistula disability weights; urinary incontinence can be due to prolapse as well). We distinguish between acute sequelae (including the pain due to POL and sepsis) and chronic sequelae (which we further divide into chronic sequelae with fistula and chronic sequelae without fistula).

When deriving disability weights $(D W)$ for each set of comorbidities $(c)$, we align with GBD methodology by calculating the multiplicative sum of the individual sequelae's $(s)$ disability weights, which is then subtracted from one: ${ }^{25}$

$$
D W_{c}=1-\prod_{s=j}^{k}\left(1-D W_{s}\right)
$$

The next step was to derive an estimate of the incidence (I) of prolonged obstructed labour $\left(I_{\text {pol }}\right)$ by country for ages 15 to 49 . Age-specific and country-specific incidence and prevalence rate estimates are provided for OL by GBD, but these estimates include cases that receive appropriate treatment with CS. The GBD study also provides age-specific and country-specific incidence and prevalence estimates for obstetric fistula. Given that our survey $(q)$ asked participants to estimate the proportion (prop) of POL cases that will develop obstetric fistula $(f)$, we can use the following relationship to derive $I_{\text {pol }}$ from GBD $(g)$ and our survey data:

$$
\frac{1}{\operatorname{Prop}_{f(q)}}=\frac{I_{p o l}}{I_{f(g)}}
$$

Equation two can be re-arranged as follows and solved for each country $(l)$ :

$$
I_{p o l, l}=\frac{I_{f(g) l}}{\operatorname{Prop}_{f(q)}}
$$

We then calculated the probability (prob) that each set of comorbidities (Probc) from box 1 will result from one case of POL, which we based on the median proportion estimate for each sequela for our baseline results. As with GBD, we assume that sequela events are independent. The country-specific incidence of each comorbidity set $\left(I_{c, l}\right)$ in 2017 can then be estimated by multiplying $I_{p o l, l}$ and Prob.

The GBD study uses a prevalence-based approach for calculating YLDs. Thus, the basic equation for calculating YLDs in 1 year is:

$$
Y L D=D W \cdot P
$$

where $\mathrm{p}=$ prevalence. Therefore, to be able to compare our estimates of YLDs with GBD estimates, we need to estimate the prevalence of each comorbidity set $\left(P_{c}\right)$. To accomplish this, we take advantage of the relationship of incidence rate, prevalence and average duration (D) for diseases by assuming a population in steady-state population:

$$
P_{c}=I_{c} \cdot D_{c}
$$

We conservatively assume that the average duration for chronic sequelae is equal to average duration of fistula (country-specific, derived from GBD results) for our baseline results. The duration for sepsis and obstructed labour events are taken directly from GBD 2017. Therefore:

$$
Y L D_{c, l}=D W_{c} \cdot P_{c, l}
$$


and YLDs for POL in each country is given by:

$$
Y L D_{p o l, l}=\sum_{c=j}^{k} Y L D_{c, l}
$$

For each country we estimated total number of YLDs and YLDs per 100000 women of reproductive age (15 to 49 years old). We perform a simple two-way sensitivity analysis by varying duration of disease $(D)$ for chronic sequelae and the proportion of POL cases that develop a sequela (mean vs median survey result) (online supplementary appendix S2). In this publication we report using median prevalence estimates from the clinician survey and a duration for chronic sequelae equal to that of the duration of fistula in each country as determined by GBD.

\section{Ethics approval}

The protocol was developed adhering to appropriate ethical principles to conduct global health research. The survey questionnaire solicited clinical opinion anonymously from key professional respondents. Therefore, on review of the initial study submission, Harvard Medical School Human Research Protection Program exempted the study from further InstitutionalReview Board review.

\section{Patient and public involvement}

Patients were not involved in the research design.

\section{RESULTS}

\section{Survey respondent demographics}

Survey responses were obtained from 132 participants, and two incomplete responses were excluded for a total sample size of 130. Since snowball sampling was used, it is not possible to estimate a survey response rate. Most responders have been providing clinical care for over 10 years $(72.7 \%)$ and work primarily in sub-Saharan Africa $(83.1 \%)$. The participants provide a wide range of services to patients with POL with the most common scope of practice being general obstetrics $(75.2 \%)$, gynaecology $(73.6 \%)$ and fistula care $(69.8 \%)$ (table 1$)$.

\section{Prevalence of comorbidities}

Estimates for 27 sequelae from POL were obtained (table 2). The most common sequelae were in the social category with inability to maintain income $(59.88 \%$, $\mathrm{IQR}=59.73$ ) and dissolution of partnership or marriage $(45.63 \%, \mathrm{IQR}=54.33)$ being the most prevalent conditions.

\begin{tabular}{|c|c|c|c|c|c|}
\hline \multicolumn{3}{|l|}{ Years as active clinician $(n=128)$} & \multicolumn{3}{|l|}{ Main region of practice $(n=130)$} \\
\hline & $\mathbf{n}$ & $\%$ & & $\mathbf{n}$ & $\%$ \\
\hline $1-5$ & 11 & 8.6 & Sub-Saharan Africa & 108 & 83.1 \\
\hline $6-10$ & 24 & 18.8 & Middle East/North Africa & 1 & 0.8 \\
\hline \multirow[t]{3}{*}{$>20$} & 47 & 36.7 & Eastern Europe/Central Asia & 0 & 0 \\
\hline & & & Latin America/Caribbean & 0 & 0 \\
\hline & & & Other & 2 & 1.5 \\
\hline \multicolumn{3}{|c|}{ Number of fistula repairs in the last year $(n=119)$} & \multicolumn{3}{|l|}{ Cases of POL managed last year $(n=125)$} \\
\hline $51-100$ & 14 & 11.8 & $51-100$ & 19 & 15.2 \\
\hline$>100$ & 31 & 26.1 & $>100$ & 10 & 8 \\
\hline I am not providing fistula repairs & 31 & 26.1 & I do not attend labour and delivery care & 31 & 24.8 \\
\hline \multicolumn{6}{|l|}{ Clinical services provided $(n=129)$} \\
\hline & $\mathbf{n}$ & $\%$ & & $\mathbf{n}$ & $\%$ \\
\hline General Obstetrics & 97 & 75.2 & General medical officer & 10 & 7.8 \\
\hline General Gynaecology & 95 & 73.6 & Task-shifted basic surgical services clinician & 5 & 3.9 \\
\hline Fistula Services & 90 & 69.8 & Urology & 22 & 17.1 \\
\hline Surgical & 50 & 38.8 & Colorectal Surgery & 8 & 6.2 \\
\hline
\end{tabular}

POL, prolonged obstructed labour. 
Table 2 Estimates of select comorbidities of prolonged obstructed labour

\begin{tabular}{|c|c|c|c|c|c|}
\hline & Median (IQR) & Mean (SD) & & Median (IQR) & Mean (SD) \\
\hline Fistula sequelae & & & Neonatal sequelae & & \\
\hline Urinary tract fistula & $23.98(54.75)$ & $39.44(35.28)$ & $\begin{array}{l}\text { Infant with sequelae of } \\
\text { intrapartum hypoxia }\end{array}$ & $13.63(16.02)$ & $25.64(28.75)$ \\
\hline Colorectal tract fistula & $6.67(5.56)$ & $11.48(13.96)$ & Stillborn child & $66.41(69.7)$ & $53.08(36.49)$ \\
\hline Pelvic floor sequelae & & & Genitourinary sequelae & & \\
\hline Incontinence without fistula & $7.66(7.19)$ & $13.15(14.75)$ & Self-reported infertility & $9.57(14.4)$ & $19.86(21.89)$ \\
\hline Incontinence with fistula & $8.6(15)$ & $24.25(29.91)$ & $\begin{array}{l}\text { Infertility due to cervical } \\
\text { issues }\end{array}$ & $7.07(5.9)$ & $13(16.01)$ \\
\hline $\begin{array}{l}\text { Prolapse without } \\
\text { incontinence }\end{array}$ & $7.69(7.64)$ & $15.76(19.91)$ & Vaginal fibrosis or stenosis & $8.92(11.15)$ & $17.04(20.84)$ \\
\hline Prolapse with incontinence & $6.53(5.44)$ & $14.4(21.86)$ & Secondary renal disease & $5.74(4.78)$ & $7.21(6.49)$ \\
\hline \multicolumn{3}{|c|}{ Infectious or inflammatory sequelae } & \multicolumn{3}{|l|}{ Musculoskeletal sequelae } \\
\hline Osteomyelitis & $5.33(4.44)$ & $7.09(9.37)$ & Foot drop & $7.22(6.02)$ & $13.47(17.68)$ \\
\hline Sepsis & $9.62(12.96)$ & $19.38(23.17)$ & Diastasis pubis & $6.04(5.04)$ & $9.36(13.29)$ \\
\hline Necrotising fasciitis & $7.02(5.85)$ & 11.39 (13.92) & Chronic pelvic pain & $11.28(12.77)$ & 17.35 (18.3) \\
\hline Other inflammatory disease & $7.08(5.9)$ & $11.43(16.15)$ & & & \\
\hline \multicolumn{3}{|l|}{ Social sequelae } & \multicolumn{3}{|l|}{ Psychological sequelae } \\
\hline Suffer from abandonment & $38.54(49.28)$ & $41.57(30.4)$ & $\begin{array}{l}\text { Anxiety or depression } \\
\text { symptoms }\end{array}$ & $23.29(31.16)$ & $33.6(27.18)$ \\
\hline Suffer from stigma & $43.57(58.67)$ & $45.13(33.34)$ & PTSD symptoms & $14.83(17.58)$ & $25.1(25.92)$ \\
\hline $\begin{array}{l}\text { Unable to maintain pre- } \\
\text { fistula income }\end{array}$ & $59.88(59.73)$ & $52.81(32.77)$ & Grieving for stillborn & $24.1(41.8)$ & $36.82(31.61)$ \\
\hline Dissolution of partnership & $45.63(54.33)$ & $46.31(31.8)$ & Other psychiatric disorders & $7.25(6.04)$ & $13.83(17.22)$ \\
\hline
\end{tabular}

PTSD, post-traumatic stress disorder.

Inter-rater reliability was determined to be 'fair' according to Landis and Koch criteria with a Kendall's W of 0.38 among all prevalence responses. Inter-rater reliability among the sequelae that were chosen for inclusion in the BOD model had a Kendall's W of 0.51 , a 'good' level of reliability according to Landis and Koch criteria.

\section{Years lost to disability}

Using a comprehensive set of comorbidities, we estimated that during 2017 in 54 countries, the sequelae of POL resulted in a total of $485,154.87 \mathrm{YLD}$, which is $37.9 \%$ more than the estimate using the GBD model. This estimate is $38 \%$ more than the previous GBD estimate. India has the largest absolute number of YLD, accounting for $21.1 \%$ of the global YLDs due to POL. When adjusting the total YLD by the population of women of reproductive age (15 to 49 years old), the country with the highest BOD per capita was South Sudan with 297.05 YLD per 100,000, which is $40.2 \%$ more than previously estimated. In Asia,
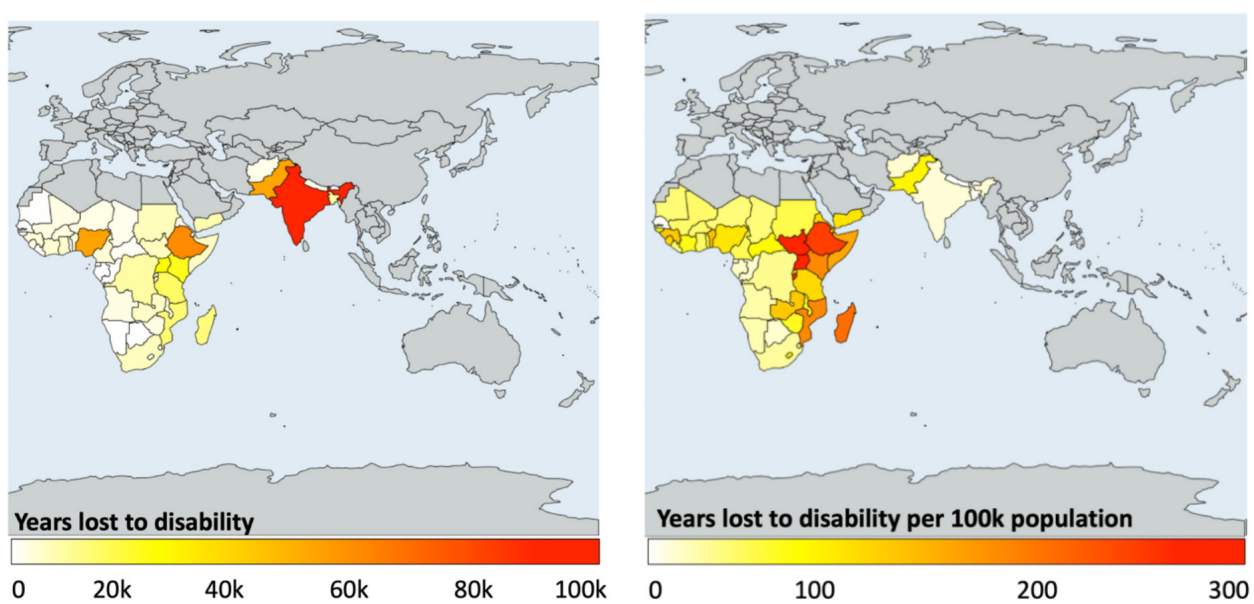

Figure 1 Geographical distribution of the total YLD and YLD per 100000 women of reproductive age in 2017. YLD,years lived with disability. 
Table 3 Comparison of burden of disease (BOD) estimates by the Global Burden of Disease (GBD) study and our new model with a more comprehensive inclusion of sequela

\begin{tabular}{|c|c|c|c|c|c|c|c|}
\hline Country & $\begin{array}{l}\text { GBD estimate } \\
\text { (YLD/100 k) }\end{array}$ & $\begin{array}{l}\text { New estimate } \\
\text { (YLD/100k) }\end{array}$ & $\begin{array}{l}\text { Difference } \\
\text { between } \\
\text { estimates (\%) }\end{array}$ & Country & $\begin{array}{l}\text { GBD estimate } \\
\text { (YLD/100k) }\end{array}$ & $\begin{array}{l}\text { New estimate } \\
\text { (YLD/100k) }\end{array}$ & $\begin{array}{l}\text { Difference } \\
\text { between } \\
\text { estimates (\%) }\end{array}$ \\
\hline Afghanistan & 22.26 & 30.01 & 34.82 & Liberia & 39.60 & 55.21 & 39.42 \\
\hline Angola & 29.97 & 41.12 & 37.20 & Madagascar & 149.55 & 206.89 & 38.34 \\
\hline Bangladesh & 15.59 & 21.09 & 35.28 & Malawi & 55.94 & 76.70 & 37.11 \\
\hline Benin & 99.65 & 137.91 & 38.39 & Mali & 43.01 & 58.57 & 36.18 \\
\hline Bhutan & 14.54 & 19.86 & 36.59 & Mauritania & 40.82 & 55.41 & 35.74 \\
\hline Botswana & 22.01 & 30.69 & 39.44 & Mozambique & 132.21 & 184.76 & 39.75 \\
\hline Burkina Faso & 42.27 & 57.55 & 36.15 & Namibia & 28.06 & 38.96 & 38.85 \\
\hline Burundi & 184.25 & 255.17 & 38.49 & Nepal & 13.08 & 17.56 & 34.25 \\
\hline Cameroon & 46.87 & 64.38 & 37.36 & Niger & 40.18 & 54.27 & 35.07 \\
\hline Cape Verde & 16.92 & 22.88 & 35.22 & Nigeria & 77.45 & 106.87 & 37.99 \\
\hline $\begin{array}{l}\text { Central African } \\
\text { Republic }\end{array}$ & 64.28 & 90.07 & 40.12 & Pakistan & 68.74 & 94.82 & 37.94 \\
\hline Chad & 39.48 & 53.97 & 36.70 & Rwanda & 86.68 & 120.00 & 38.44 \\
\hline Comoros & 171.82 & 237.70 & 38.34 & $\begin{array}{l}\text { Sao Tome and } \\
\text { Principe }\end{array}$ & 16.38 & 21.98 & 34.19 \\
\hline Congo & 22.07 & 30.41 & 37.79 & Senegal & 14.20 & 19.33 & 36.13 \\
\hline Cote d'Ivoire & 58.99 & 81.67 & 38.45 & Sierra Leone & 85.60 & 119.01 & 39.03 \\
\hline $\begin{array}{l}\text { Democratic Republic of } \\
\text { the Congo }\end{array}$ & 35.09 & 48.51 & 38.24 & Somalia & 114.90 & 159.28 & 38.62 \\
\hline Djibouti & 96.82 & 133.48 & 37.86 & South Africa & 32.08 & 44.63 & 39.12 \\
\hline Equatorial Guinea & 16.91 & 22.95 & 35.72 & South Sudan & 211.86 & 297.05 & 40.21 \\
\hline Eritrea & 82.39 & 114.07 & 38.45 & Sudan & 48.56 & 67.25 & 38.49 \\
\hline Ethiopia & 176.72 & 244.54 & 38.38 & Swaziland & 30.18 & 41.89 & 38.80 \\
\hline Gabon & 23.56 & 32.63 & 38.50 & Tanzania & 85.45 & 117.63 & 37.66 \\
\hline Ghana & 43.36 & 59.26 & 36.67 & The Gambia & 35.38 & 48.78 & 37.87 \\
\hline Guinea & 94.43 & 131.07 & 38.80 & Togo & 52.07 & 71.65 & 37.60 \\
\hline Guinea-Bissau & 60.86 & 84.12 & 38.22 & Uganda & 207.20 & 286.73 & 38.38 \\
\hline India & 20.72 & 28.41 & 37.11 & Yemen & 76.82 & 108.18 & 40.82 \\
\hline Kenya & 132.70 & 183.75 & 38.47 & Zambia & 94.68 & 130.76 & 38.11 \\
\hline Lesotho & 71.10 & 100.55 & 41.42 & Zimbabwe & 56.08 & 78.19 & 39.43 \\
\hline
\end{tabular}

YLD, years lived with disability.

Yemen has the highest per capita BOD with 108.18 YLD per 100000. Nepal (17.55 YLD/100 000) and Senegal (19.32 YLD/100 000) have the lowest per capita BOD in Asia and Africa, respectively. Geographical variations of absolute YLDs and YLDs per 100000 women are shown in figure 1. Burden of disease due to YLD for individual countries comparing the GBD model estimates and the estimates with the updated model with more comprehensive sequelae are on table 3 .

\section{DISCUSSION}

\section{Main findings}

Our study estimates the global prevalence of a comprehensive set of sequelae associated with POL, providing a more representative estimate of the burden of disease. The survey results suggest that the most prevalent sequelae is urinary tract fistula, affecting approximately
24\% (IQR=54.8) of women. Obstetric fistula is often considered as the most devastating consequence of POL, and women often also suffer from incontinence $(8.6 \%$, $\mathrm{IQR}=15)$ and/or prolapse $(6.5 \%, \mathrm{IQR}=5.4)$. Our results suggest that $66.4 \% \quad(\mathrm{IQR}=69.7)$ of women with $\mathrm{POL}$ have a stillbirth and $13.6 \%(\mathrm{IQR}=13.6)$ have an infant suffering sequelae of intrapartum hypoxia. Psychological and social sequelae were estimated to have a higher prevalence than most physical sequelae with grieving for stillborn, anxiety or depression symptoms estimated to be prevalent in approximately one-quarter of women. The most common social sequelae is loss of income, affecting approximately $59.9 \%(\mathrm{IQR}=59.7)$ of women, followed by stigma in $43.6 \%(\mathrm{IQR}=58.7)$ of patients. The estimates obtained for acute sequela such as fistula and sepsis and chronic sequelae such as incontinence, infertility, chronic pelvic pain and foot drop, were used to determine 
that the current estimates of the GBD study underestimate the disability from POL by at least $38 \%$. Since we followed the GBD study methodology we were restricted on the sequela from POL that we could include, and this remains a conservative estimate.

\section{Interpretation}

Our survey results are consistent with literature estimates on the sequelae experienced by women with POL. For example, the percentage of stillbirths has been estimated to be $78 \%$ to $96 \%$ in women who develop obstetric fistula. ${ }^{29} 30$ The economic impact of POL disproportionately affects poor women who cannot access timely emergency obstetrical care, including caesarean delivery, for whom such services are too costly. POL sequelae further reduce income-earning activities, compounded by high out-of-pocket expenses that prevent access to fistula care. ${ }^{31-33}$ Consistent with our results, a longitudinal obstetric fistula study has shown that POL survivors' psychosocial health and quality of life are greatly affected by high prevalence of stigma, disruption of social relations and depression symptoms. ${ }^{19}$ Evidence suggests that treatment of physical symptoms results in significant improvement of psychological health, but targeted reintegration services and psychosocial support is needed to support women after POL regardless of their physical comorbidities. It should be noted that much of this literature focusses on women with fistula, with limited exploration of the consequences to women who have experienced other sequelae of POL.

The significant detrimental impact of POL sequelae such as fistula, incontinence and psychosocial sequelae have been captured in qualitative studies. ${ }^{34}{ }^{35}$ However, quantifying the disability experienced by these women remains a challenge. Global progress in maternal health has traditionally relied on maternal and neonatal mortality as metrics to track progress ${ }^{36-38}$ However, as mortality decreases, an increased focus on near-miss events, maternal severity index and preventable morbidity has emerged. ${ }^{39}$ Similarly, the estimates for the global burden of disease of POL, characterised in disability-adjusted life years, are evolving from being driven by years of life lost when women would often not survive complications of pregnancy, to being driven by YLD as more women survive POL and live with chronic disability. ${ }^{25}$ Measuring health loss from disability is complex, reflecting persistent failure to provide timely access to caesarean section to avert POL, as well as illustrating a failure to address all sequelae of POL.

\section{Research, programmatic, funding and policy recommendations}

Most of the outcome data on interventions to address POL sequelae focus on obstetric fistula and are sparse in elucidating other comorbidities and alleviation of barriers to timely care. ${ }^{40}$ Advancing research on the prevalence, management and outcomes of these sequelae in a similar fashion in which fistula repair has been studied could improve service delivery to these patients. POL is a rare event that is challenging to measure and as a result some countries have started including fistula indicators as part of their national health information systems or collecting data as part of their Demographic Health Survey. ${ }^{41}$ Developing health utility values for psychosocial factors would allow for inclusion of more sequelae, that are known to have a high prevalence, to be included in the estimates of BOD for POL. Robust data collection and research around POL will be necessary to strengthen service delivery and policy development.

Comprehensive clinical and public health programmes that address physical sequelae beyond fistula to include physical comorbidities, psychosocial sequelae, educational and vocational training for reintegration back into society and developmental screening for surviving infants are essential to holistically address the disability from POL. At the community level, education programmes on POL could decrease stigma and promote care seeking behaviour to prevent POL and to treat the entire maternal and newborn spectrum of sequelae from it. Despite an increase in antenatal care and institutional deliveries, access to timely high-quality obstetric surgical care remains challenging. As a result, even when women access healthcare facilities when in labour, lack of surgical capacity and quality results in preventable POL. For example, a study in Uganda showed that $50.9 \%$ of women acquired obstetric fistula in their first delivery despite $94.3 \%$ having received antenatal care. ${ }^{42}$ Furthermore, rises in iatrogenic fistula have been reported, therefore as surgical capacity is scaled up, a concurrent investment on quality of care is essential to prevent inflicting harm on women ${ }^{43}$

Treatment of obstetric fistula has received significant attention by the global community including the United Nations Population Fund's (UNFPA) Campaign to End Fistula in 2003 and the United Nations Secretary-General 2018 call to action to end obstetric fistula by $2030 .{ }^{44} 45$ Despite large amounts of funding and programming for fistula treatment, many of the other comorbidities resulting from POL have been neglected. This illustrates how global funding efforts, guided by vertical interventions, may be poorly aligned with actual BOD. ${ }^{46}$ A more comprehensive understanding of the $\mathrm{BOD}$ associated with $\mathrm{POL}$, as outlined by our results, could guide programmatic and funding allocation by informing policymakers, donors and other global stakeholders on the need to invest in comprehensive health services.

Several countries have national obstetric fistula policies that are undermined by gaps in programming and poor alignment with existing health and human rights policies. ${ }^{47}$ Most of these national fistula strategies are designed for fistula treatment without an equally effective strategy for POL prevention or treatment via safe and comprehensive emergency obstetric care, undermining the goal of a 'fistula-free generation' ${ }^{47}$ We recommend POL strategies that are well-integrated within national health strategies for maternal and surgical care to ensure funding, implementation and coordination with other services. Preventing and addressing the BOD elucidated 
by our study support the sustainable development goals-era mandate to end not only fistula, but preventable childbirth-related morbidity and mortality. ${ }^{44} 4849$ While the public health approach to eradicate POL must include initiatives to delay the age of marriage, improve girls' and women's nutrition, assure girls' education, reliable provision of family planning services, support for women's economic empowerment and other genderbased transformations, all such efforts will not have their full desired impacts without concurrent strengthening of access to timely, affordable and high-quality obstetric interventions that include indicated, safe surgical care. ${ }^{48}$

\section{Strengths and limitations}

We obtained prevalence estimates from a multidisciplinary group of participants, working mostly in subSaharan Africa and South Asia, with extensive experience working with women affected by POL. As a result, we expect their assessments to provide an accurate estimate of patients' sequelae. Although a multidisciplinary sample was targeted, the use of global networks of fistula care resulted in the majority of participants being surgical providers. Larger participation of other professions such as community health workers and midwives, may have revealed different results. Our results remain practitioner estimates, and facility level outcomes and patient-reported outcomes would further strengthen our results. Furthermore, this approach excludes the women who are not accessing health facilities. Future validation of the survey will be required to strengthen morbidity estimates of POL. The survey was distributed in English as most clinicians have higher education and speak the language due to the global nature of fistula provider networks. However, it is likely that English-speaking clinicians are more likely to work at large, regional centres while most women who suffer from POL are in more remote areas, therefore impacting our results. Estimation of the BOD due to POL was structured to match the Institute for Health Metrics and Evaluation robust GBD methodology, enabling meaningful comparisons to prior estimates. However, the list of sequelae included in the new BOD model was limited to those for which a disability weight exists, which restricted the inclusion of many comorbidities into the model, particularly psychosocial sequelae. All these limitations suggest that, despite providing a more comprehensive BOD model, our analysis still underestimates the true disability experienced by women and newborns as a result of POL.

\section{CONCLUSION}

POL is preventable, and when untreated, results in a wide range of debilitating physical and psychosocial sequelae. We estimated a more comprehensive BOD resulting from POL to better guide research and policy, but this likely remains an underestimate of disabilities women face, particularly from psychosocial sequelae. High-quality surgical and anaesthesia care are urgently needed as part of an essential component of maternal health systems. This will both prevent POL and treat all of the needs of the mothers and newborns who have survived POL, far too often into a lifetime of tragic suffering caused by preventable disability.

\section{Author affiliations}

${ }^{1}$ Program in Global Surgery and Social Change, Department of Global Health and Social Medicine, Harvard Medical School, Boston, Massachusetts, United States ${ }^{2}$ Department of Obstetrics \& Gynecology, University of Alberta, Edmonton, Alberta, Canada

${ }^{3}$ Miller School of Medicine, University of Miami, Miami, Florida, USA

${ }^{4}$ Department of Obstetrics and Gynecology, Korle Bu Teaching Hospital, Accra, Greater Accra, Ghana

${ }^{5}$ Fistula Care Plus, EngenderHealth, Washington, District of Columbia, USA

${ }^{6}$ EngenderHealth Inc, Dhaka, Bangladesh

${ }^{7}$ Center for Global Surgery Evaluation, Massachusetts Eye and Ear Infirmary, Boston, Massachusetts, USA

${ }^{8}$ Department of Otolaryngology, Massachusetts Eye and Ear Infirmary, Boston, Massachusetts, United States

Twitter Lina Roa @LinaRoaS

Acknowledgements The authors thank Mary Ellen Stanton and Erin Mielke of USAID for their review of this manuscript.

Contributors LR, LC and BCA conceived the study. LR, GG, VT and LR developed the survey. $L C, N H$ and GG collected data. $L R, L C$ and BCA conducted the analysis. $\mathrm{LR}$ and $\mathrm{BCA}$ drafted the manuscript. All authors made significant contributions to the manuscript and meet authorship criteria.

Funding Lina Roa received support from the Ronda Stryker and William Johnston Global Surgery Fellowship Fund. This study was partly supported by the American people through the United States Agency for International Development (USAID) associate cooperative agreement AID-OAA-A14-00013. The opinions expressed are those of the authors and do not necessarily reflect the views of USAID or the United States Government.

Disclaimer Blake Alkire reports grants from Mercy Ships. No other disclosures were reported.

Competing interests BCA reports grants from Mercy Ships, these did not influence the submitted work.

Patient and public involvement Patients and/or the public were not involved in the design, or conduct, or reporting, or dissemination plans of this research.

Patient consent for publication Not required.

Provenance and peer review Not commissioned; externally peer reviewed.

Data availability statement Data from the survey results are available upon request. Data used for burden of disease modelling is available at the Global Burden of Disease Study website from the Institute for Health Metrics and Evaluation and is available open access.

Open access This is an open access article distributed in accordance with the Creative Commons Attribution Non Commercial (CC BY-NC 4.0) license, which permits others to distribute, remix, adapt, build upon this work non-commercially, and license their derivative works on different terms, provided the original work is properly cited, appropriate credit is given, any changes made indicated, and the use is non-commercial. See: http://creativecommons.org/licenses/by-nc/4.0/.

\section{ORCID iD}

Lina Roa http://orcid.org/0000-0001-6552-4452

\section{REFERENCES}

1 WHO. Education material for teachers of midwifery midwifery education modules-second edition, 2008.

2 Goodwin WE, Scardino PT. Vesicovaginal and ureterovaginal fistulas: a summary of 25 years of experience. J Urol 1980;123:370-4.

3 Langkilde NC, Pless TK, Lundbeck F, et al. Surgical repair of vesicovaginal fistulae--a ten-year retrospective study. Scand J Urol Nephrol 1999;33:100-3. 
4 Ali UA, Norwitz ER. Vacuum-assisted vaginal delivery. Rev Obstet Gynecol 2009;2:5-17.

5 Alkire BC, Vincent JR, Burns CT, et al. Obstructed labor and caesarean delivery: the cost and benefit of surgical intervention. PLoS One 2012;7:e34595.

6 Dutta S, Blakemore KJ, Johnson CT. The Cost-Effectiveness of Operative Delivery in the Management of Obstructed Labor [323]. Obstetrics \& Gynecology 2015;125:102S-3.

7 Adam T, Lim SS, Mehta S, et al. Cost effectiveness analysis of strategies for maternal and neonatal health in developing countries. BMJ 2005;331:1107.

8 Jha P, Bangoura O, Ranson K. The cost-effectiveness of forty health interventions in guinea. Health Policy Plan 1998;13:249-62.

9 Dolea C, Abouzahr C. Global burden of obstructed labour in the year 2000. Global Burden of Disease 2000.

10 Harrison MS, Pasha O, Saleem S, et al. A prospective study of maternal, fetal and neonatal outcomes in the setting of cesarean section in low- and middle-income countries. Acta Obstet Gynecol Scand 2017;96:410-20.

11 WHO. Who recommendations for augmentation of labor, 2015. Available: https://www.who.int/reproductivehealth/publications/ maternal_perinatal_health/augmentation-labour/en/

12 Tripathi V, Pett C. Research Consultation: Catheterization after Obstructed Labor [Internet], 2015. Available: https://fistulacare. org/wp-fcp/wp-content/uploads/2018/03/FC_CathConsultation 2015Report_Posting.pdf

13 Say L, Chou D, Gemmill A, et al. Global causes of maternal death: a who systematic analysis. Lancet Glob Health 2014;2:e323-33.

14 McClure EM, Saleem S, Pasha O, et al. Stillbirth in developing countries: a review of causes, risk factors and prevention strategies. J Matern Fetal Neonatal Med 2009;22:183-90.

15 Lawn JE, Blencowe H, Pattinson R, et al. Stillbirths: where? when? why? how to make the data count? Lancet 2011;377:1448-63.

16 LaRosa DA, Ellery SJ, Walker DW, et al. Understanding the full spectrum of organ injury following intrapartum asphyxia. Front Pediatr 2017;5:16.

17 van Handel M, Swaab H, de Vries LS, et al. Long-Term cognitive and behavioral consequences of neonatal encephalopathy following perinatal asphyxia: a review. Eur J Pediatr 2007;166:645-54.

18 Arrowsmith S, Hamlin EC, Wall LL. Obstructed labor injury complex: obstetric fistula formation and the multifaceted morbidity of maternal birth trauma in the developing world. Obstet Gynecol Surv 1996;51:568-74.

19 El Ayadi AM, Barageine J, Korn A, et al. Trajectories of women's physical and psychosocial health following obstetric fistula repair in Uganda: a longitudinal study. Trop Med Int Health 2019;24:53-64.

20 Fantu S, Segni H, Alemseged F, Incidence AF. Incidence, causes and outcome of obstructed labor in jimma university specialized Hospital. Ethiop J Health Sci 2010;20:145-51.

21 Ahmed S, Holtz SA. Social and economic consequences of obstetric fistula: life changed forever? Int J Gynaecol Obstet 2007;99 Suppl 1:S10-15.

22 Bashah DT, Worku AG, Mengistu MY. Consequences of obstetric fistula in sub Sahara African countries, from patients' perspective: a systematic review of qualitative studies. BMC Womens Health 2018;18:106.

23 Sonderman KA, Citron I, Albutt K, et al. USAID: current support for global surgery and implications of reform. Surgery 2018;164:1147-55.

24 Intensifying efforts to end obstetric fistula-Report of the Secretary General, 2016. Available: http://www.endfistula.org/sites/default/ files/pub-pdf/UNGA71 - Intensifying Efforts to End Obstetric Fistula A-71-306.pdf

25 GBD 2017 Disease and Injury Incidence and Prevalence Collaborators. Global, regional, and national incidence, prevalence, and years lived with disability for 354 diseases and injuries for 195 countries and territories, 1990-2017: a systematic analysis for the global burden of disease study 2017. Lancet 2018;392:1789-858.

26 Harris PA, Taylor R, Thielke R, et al. Research electronic data capture (REDCap)--a metadata-driven methodology and workflow process for providing translational research informatics support. $J$ Biomed Inform 2009;42:377-81.
27 R Core Team. A language and environment for statistical computing. Vienna, Austria: R Foundation for Statistical Computing, 2018.

28 RStudio Team. RStudio: integrated development for R. Boston, MA: RStudio, Inc., 2016.

29 Tebeu PM, Fomulu JN, Khaddaj S, et al. Risk factors for obstetric fistula: a clinical review. Int Urogynecol J 2012;23:387-94.

30 Ahmed S, Anastasi E, Laski L. Double burden of tragedy: stillbirth and obstetric fistula. Lancet Glob Health 2016;4:e80-2.

31 Ravit M, Philibert A, Tourigny C, et al. The hidden costs of a free caesarean section policy in West Africa (Kayes region, Mali). Matern Child Health J 2015;19:1734-43.

32 Keya KT, Sripad P, Nwala E, et al. "Poverty is the big thing": exploring financial, transportation, and opportunity costs associated with fistula management and repair in Nigeria and Uganda. Int $J$ Equity Health 2018;17:70.

33 Okoye UO, Emma-Echiegu N, Tanyi PL. Living with vesico-vaginal fistula: experiences of women awaiting repairs in Ebonyi state, Nigeria. Tanzan J Health Res 2014;16:322-8.

34 Changole J, Thorsen VC, Kafulafula U. "I am a person but I am not a person": experiences of women living with obstetric fistula in the central region of Malawi. BMC Pregnancy Childbirth 2017;17:433.

35 Mwini-Nyaledzigbor PP, Agana AA, Pilkington FB. Lived experiences of Ghanaian women with obstetric fistula. Health Care Women Int 2013;34:440-60.

36 GBD 2016 SDG Collaborators. Measuring progress and projecting attainment on the basis of past trends of the healthrelated sustainable development goals in 188 countries: an analysis from the global burden of disease study 2016. Lancet 2017;390:1423-59.

37 Alkema L, Chou D, Hogan D, et al. Global, regional, and national levels and trends in maternal mortality between 1990 and 2015, with scenario-based projections to 2030: a systematic analysis by the un maternal mortality estimation Inter-Agency group. Lancet 2016;387:462-74.

38 Sustainable development Goals-United nations development programme. Available: http://www.undp.org/content/undp/en/home/ sustainable-development-goals.html

39 Souza JP, Cecatti JG, Haddad SM, et al. The who maternal nearmiss approach and the maternal severity index model (MSI): tools for assessing the management of severe maternal morbidity. PLoS One 2012;7:e44129.

40 Baker Z, Bellows B, Bach R, et al. Barriers to obstetric fistula treatment in low-income countries: a systematic review. Trop Med Int Health 2017;22:938-59.

41 Tunçalp Özge, Tripathi V, Landry E, et al. Measuring the incidence and prevalence of obstetric fistula: approaches, needs and recommendations. Bull World Health Organ 2015;93:60-2.

42 Meurice M, Genadry R, Heimer C, et al. Social experiences of women with obstetric fistula seeking treatment in Kampala, Uganda. Ann Glob Health 2017;83:541-9.

43 Raassen TJIP, Ngongo CJ, Mahendeka MM. latrogenic genitourinary fistula: an 18-year retrospective review of 805 injuries. Int Urogynecol J 2014;25:1699-706.

44 UN General Assembly. Intensifying efforts to end fistula within a generation. Report of the Secretary General. Available: http://www. endfistula.org/sites/default/files/pubpdf/SG_Report_Fistula_2018 FINAL.pdf

45 UNFPA. Campaign to end fistula: the year in review. Available: https://www.unfpa.org/publications/campaign-end-fistula-yearreview

46 Gutnik L, Dieleman J, Dare AJ, et al. Funding allocation to surgery in low and middle-income countries: a retrospective analysis of contributions from the USA. BMJ Open 2015;5:e008780.

47 Amodu OC, Salami BO, Richter MS. Obstetric fistula policy in Nigeria: a critical discourse analysis. BMC Pregnancy Childbirth 2018;18:269.

48 Romanzi L, Meara JG, Anastasi E, et al. Meeting the SDG challenge to end fistula and preventable childbirth-related morbidity and mortality. Lancet Glob Health 2019;7:e835-6.

49 Roa L, Jumbam DT, Makasa E, et al. Global surgery and the sustainable development goals. Br J Surg 2019;106:e44-52. 